\title{
College Students' Use of Reporting Verbs and Verb Complements in Academic Papers
}

\author{
Loretta Gray* \\ Department of English, Central Washington University, 400 East University Way, Ellensburg, WA, \\ USA 98926-7558 \\ *E-mail of the author: Loretta.Gray@cwu.edu
}

\begin{abstract}
College students are required to cite sources they incorporate into their research papers. Sources integrated into sentences are to have the author's name (or a pronoun referring to the author), a reporting verb, and a verb complement. Although most students are able to choose an appropriate verb, some students use unconventional verb complements. This small-scale qualitative study contributes to the growing research on the use of reporting verbs in academic discourse by looking at these unconventional verb + complement patterns to ascertain the types of patterns that students have not fully acquired.
\end{abstract}

Keywords: reporting verbs, verb complements, academic writing

DOI: $10.7176 /$ JLLL/55-04

Publication date: April $30^{\text {th }} 2019$

\section{Introduction}

Students writing college-level research papers are expected to cite their sources when they paraphrase, summarise, or synthesise information from these sources (Modern Language Association, 2016). Citations may be integral (noted in the sentence) or non-integral (parenthetical). Some students have already learned this skill by the time they start their first year, but others find citation challenging, even when English is their primary language. A challenge related to integral citations is matching reporting verbs (RVs) with their complements. RVs are those verbs used in attributive tags (also called "signal phrases"). These tags attribute words or ideas to a specific author (e.g., Smith reports/states/argues).

Because many verb + complement patterns found in academic discourse are seldom used in everyday English, a student may use a verb with an unexpected complement; for example, the following sentence includes a that-clause after the verb, instead of a noun phrase:

*AUTHOR expresses that the consumer needs to comprehend the information being provided in order for the Web to be useful. (student example)

AUTHOR expresses his belief that the consumer needs to comprehend the information being provided in order for the Web to be useful. (revised example)

It would be easy to hypothesize that students simply overgeneralize the said-that pattern (AUTHOR said that ...), but other data weaken this hypothesis, as in this sentence, which includes a noun phrase followed by an infinitive instead of a subjunctive that-clause:

*AUTHOR demands readers to take action against the Digital Divide. (student example)

AUTHOR demands that readers take action against the Digital Divide. (revised example)

Researchers have examined the choice of RV in academic articles (e.g., Agbalo, 2017; Bloch, 2010; Hyland, 2002; Thompson \& Ye, 1991; Yeganeh \& Boghayeri, 2015). This study builds on previous research by looking closely at the verb complements used by college students in their academic papers. Hyland (2002) emphasizes that "the selection of a particular reporting verb is a delicate choice as it is a crucial means of both situating one's work appropriately and communicating with one's peers effectively " (p. 130). The verb complement is part of that choice. As students acquire isolated vocabulary expected in academic discourse, they could benefit from learning to use words in appropriate grammatical patterns as well. The goal of this study is to discover the types of reporting verbs and complementation patterns that writing teachers may need to help students learn.

De Bot and Schrauf (2009) state that "there is hardly any research on language development in the age range from 18 till 55" (p. 2). This study would thus provide much-needed information on the language acquisition of students primarily between the ages of 18 and 22. The learning of vocabulary and the learning of grammar are intertwined. When students acquire lexical items, they acquire the corresponding grammatical patterns, though not necessarily simultaneously. In the process of learning new verbs, students may go through a period when they use non-target complement patterns as their innate knowledge of the grammatical system of English develops.

\subsection{Reporting Verbs in Academic Prose}

Biber et al. (1999) revealed that academic prose differs from other registers (i.e., conversation, fiction, and news writing) in a number of ways, one of which is the distribution of verbs. In fact, academic prose contains 
relatively few verbs (Biber, 2006), though there are types of verbs that appear considerably more often in academic prose than in the other registers: forms of be and become, prepositional verbs (depend on, believe in, rely on), verbs with inanimate subjects, verbs in the passive voice, and specific lexical verbs such as describe, suggest, assume, and indicate. Biber et al. examined these types of lexical verbs more closely and found that causative, mental, and communication verbs occur frequently in textbooks regardless of the discipline for which they are written (business, education, humanities, natural science, or social science). Thus, while academic writing can vary according to discipline, there are conventions at the sentential level that cross these disciplinary boundaries.

Researchers who study RVs typically divide them into categories according to criteria. If the focus is on semantics (Charles, 2006; Friginal, 2013; Kwon, Staples, \& Partridge, 2018), four categories are common: ARGUE verbs (argue, claim, maintain), THINK verbs (think, believe, realise), SHOW verbs (show, indicate, reveal) and FIND (find, discover, learn) verbs.

If the focus is on processes depicted by the verbs, typically three main groups are established (Agbaglo, 2017; Hyland, 2002; Thomas \& Hawes, 1994; Thompson \& Ye, 1991). Because category labels are not consistent, alternative labels are provided here:

Research. Verbs that refer to research activities such as analyse, synthesise, examine, and observe belong in this category.

Cognition/Mental. Constituting this category are verbs that refer to mental activity such as think, believe, and assume.

Discourse/Textual. Verbs such as mention, note, and state focus on spoken or written expression.

Thomas and Ye (1991) state that these three groups all refer to acts of the reported author, not the reporting writer. They mention two other groups of verbs that can be attributed, albeit indirectly, to the reporting writer:

Comparing. Verbs such as anticipate, agree with, and counter may be used by the reporting writer when comparing and contrasting sources or when synthesising information.

Theorizing. To develop a line of argument, a reporting writer may use verbs such as support, confirm, and undermine

Of course, verbs do not fit neatly into categories. Context will determine the process referred to by the verbs. This study's primary focus is on the form of the complement following the reporting verb. Thompson and Ye's (1991) categories will be used to determine whether verbs in the data can be considered RVs in the first place.

\subsection{Verb Complement Patterns}

Quirk, Greenbaum, Leech, and Svartvick (1985) detail 25 different complementation types, which they group into four different categories: Copular (3), Monotransitive (9), Complex Transitive (7), and Ditransitive (6). Only the last three categories are relevant to the study of reporting verbs. Integral citations generally include an author's name or a pronoun referring to the author in the subject position followed by a transitive reporting verb and its complement, normally an object.

Collins Cobuild Dictionary (1995) lists complementation patterns for each verb entry, an especially useful feature given that many verbs can take more than one complementation pattern. Describe, for example, is listed as having a range of complements: $\mathrm{V}$ wh, $\mathrm{V} \mathrm{n}, \mathrm{V}-\mathrm{ing}, \mathrm{V} \mathrm{n}$ as $\mathrm{n}, \mathrm{V} \mathrm{n}$ as adj, $\mathrm{V} \mathrm{n}$ as -ing. The reporting verbs found in this study were compared against the entries in Collins for two purposes: first, to determine what the conventional patterns were and, second, to confirm that the pattern used by the student was unconventional.

\section{Methodology}

The methodology for this qualitative study has two parts. The first is based on my experience reading student papers and collecting sentences in which the verb + complement pattern was unconventional. Colleagues also graciously sent me problematic sentences they encountered. These examples all were produced by native speakers attending college.

The second part is a corpus-driven study of 110 student essays collected in electronic form in the fall of 2007 and the winter of 2008. These essays were chosen from 207 essays submitted by students attending 10 different colleges in the United States. Many of the original essays forming the original corpus had to be discarded because of duplication or technical complications. No other demographic information was collected.

I used Graphic Online Language Diagnostic (GOLD) from The Pennsylvania State University to both create a corpus and to search the corpus. The search procedure was based on Hyland's (2002) methodology: (1) a search for the name of authors listed in bibliographies and (2) a search for third-person pronouns. The examples found in the corpus were written by college students; however, information about native-speaker status was not available.

Once the list of verbs and sample sentences was established, I compared the verb + complementation patterns used by the students to those listed for specific verbs in Collins Cobuild Dictionary to confirm that the patterns were unconventional. To bolster this confirmation with updated information, I used the interface at 
www.wordandphrase.info.

\section{Results}

The following reporting verbs appeared at least once with an unconventional complement: address, argue, articulate, assume, bring up, conclude, convey, debate, define, demand, describe, display, emphasise, exemplify, express, give, illustrate, include, note, reason, refer, state, stress, study, and take.

The majority of the unconventional complementation patterns produced by the students differed from the conventional patterns in the following ways:

1. Use of a that-clause or a wh-clause (AUTHOR addresses that the stereotypes of language that have been placed on both genders are merely generalizations.)

Verbs used: address, convey, describe, display, exemplify, express, include, refer, take

2. Use of a prepositional or adverbial particle (AUTHOR articulates on quite a few subtopics of the nature of conversation.)

Verbs used: articulate, bring up, debate, emphasis, give note, stress

3. Use of an infinitive or a noun + infinitive (AUTHOR concludes to say that, despite the obstacles, women have gained initiative.)

Verbs used: conclude, define, demand

4. Use of a noun phrase (AUTHOR also states the five main puzzle pieces to technology as content, literacy, pedagogy, and community.)

Verbs used: argue, reason, state

5. Use of the verb without a complement (AUTHOR assumes and throws claims out, such as, when he explains his opinion on sub-Saharan Africa.)

Verbs used: assume, study

The complements for argue and illustrate were unconventional due to semantic restrictions. Two students used argue about when only one person was mentioned (e.g., AUTHOR argues about how the Internet can provide a sense of community for various Internet users). Two other students used illustrate with a human subject when an inanimate subject is called for (e.g., AUTHOR again illustrates how the doctors in five different nations helped cure SARS disease).

\section{Discussion}

This small-scale study indicates that although reporting verbs are used in college-level papers written by students, they are sometimes followed by unconventional complement patterns. The pattern chosen by the student writers is not predictable. Although the that-clause is the most common pattern chosen, prepositional phrases, infinitives, and noun phrases were also used.

There are a number of possible reasons for the variation. The overgeneralization of the that-clause could account for several of the unconventional patterns. A student accustomed to conclude that might believe that include patterns the same way. Students may also be substituting words found in a thesaurus-state for mention could result in states the five main puzzle pieces as . . Another possible reason is that student writers are cutting and pasting information into a sentence.

\section{Conclusion}

The good news is that students are, for the most part, on the right track. All the verbs in the data (articulate, convey, and exemplify) are on either the General Service List, the Academic Word List, or the Academic Vocabulary List. With more exposure to academic prose and with focused instruction, students should be able to choose not only the appropriate verb but also the appropriate complement and thereby clearly acknowledge their sources and successfully communicate with an academic audience.

Studies with larger corpora are needed to verify the findings reported here. In addition, further research into the 'awkward' sentences that college students produce, such as relative clauses or compound constructions, would provide useful information for writing teachers and for researchers studying language development in young adults.

\section{References}

Agbalo, E. (2017). The types and the frequencies of reporting verbs in research articles written by lecturers in a Ghanaian University. Journal of Literature, Languages and Linguistics, 34, 51-57.

Biber, D. (2006). University language: A corpus-based study of spoken and written registers. Amsterdam: John Benjamins.

Biber, D., Johansson, S., Leech, G., Conrad, S., Finegan, E., \& Quirk, R. (1999). Longman grammar of spoken and written English. White Plains, NY: Longman.

Bloch, J. (2010). A concordance-based study of the use of reporting verbs as rhetorical devices in academic 
papers. Journal of Writing Research, 2(2), 219-244.

Charles, M. (2006). The construction of stance in reporting clauses: A cross-disciplinary study of theses. Applied Linguistics, 27(3), 492-518.

Collins Cobuild English dictionary. (1995). London: HarperCollins.

Coxhead, A. AWL sublist families. Retrieved from https://www.victoria.ac.nz/lals/resources/ academicwordlist/sublists

Davis, M., \& Gardner, D. (2013). Academic Vocabulary lists. Retrieved from https://www.wordandphrase.info/academic/frequencyList.asp

De Bot, K., \& Schrauf, R. W. (2009). Language development over the lifespan. New York: Routledge.

Friginal, E. (2013). Developing research report writing skills using corpora. English for Specific Purposes, 32(4), 208-220.

Graphic Online Language Diagnostic. (2019). State College: The Pennsylvania State University.

Hyland, K. (2002). Activity and evaluation: Reporting practices in academic writing. In J. Flowerdew (Ed.), Academic discourse (pp. 115-130). London: Longman.

Kwon, M. H., Staples, S., \& Partridge, R. S. (2018). Source work in the first-year L2 writing classroom: Undergraduate L2 writers' use of reporting verbs. Journal of English for Academic Purposes, 34, 86-96.

Modern Language Association. (2016). MLA handbook (8th ed.). New York: Author.

Thomas, S., \& Hawes, T. P. (1994). Reporting verbs in medical journal articles. English for Specific Purposes, 13(2).

Thompson, G., \& Ye, Y. (1991). Evaluation in the reporting verbs used in academic papers. Applied Linguistics, $12(4), 365-382$.

Quirk, R., Greenbaum, S., Leech, G., \& Svartvik, J. (1985). A comprehensive grammar of the English language. Harlow, England: Longman.

West, M. (1953). A general service list of English words. London: Longman, Green.

Yeganeh, M. T., \& Boghayeri, M. (2015). The Frequency and Function of Reporting Verbs in Research Articles Written by Native Persian and English Speakers. Procedia-Social and Behavioral Sciences, 192, 582-586. 